\title{
A Study of Construction Techniques of Tibetan Villages in Saiergu Town
}

\author{
Jiayu Shang, Bin Zhao* \\ Architecture and Urban Planning College, Southwest Minzu University, Chengdu, China \\ Email: *287476737@qq.com
}

How to cite this paper: Shang, J.Y. and Zhao, B. (2019) A Study of Construction Techniques of Tibetan Villages in Saiergu Town. Open Journal of Social Sciences, 7, 21-27.

https://doi.org/10.4236/jss.2019.71002

Received: November 30, 2018

Accepted: January 5, 2019

Published: January 8, 2019

Copyright $\odot 2019$ by authors and Scientific Research Publishing Inc. This work is licensed under the Creative Commons Attribution International License (CC BY 4.0).

http://creativecommons.org/licenses/by/4.0/

\section{(c) (i) Open Access}

\begin{abstract}
Traditional residential buildings of Tibetan nationality have been applauded by domestic and international architectural fields for their solid, majestic, dignified and nice features. Raw materials for construction of Tibetan buildings, such as stones, wood and mud, are all taken from nature. Construction method is original and simple hand measurement method. It is impressed by the people all around the world that a strong building that has not been moved for 100 years is built only with simple material and wall building method. At the era of rapid economic development, more and more traditional residential houses are being destroyed. Traditional construction techniques are gradually disappearing and assimilated by modern construction. In this paper, the author takes Tibetan Villages in Saiergu Town of Aba state in Sichuan province as main research object, and explores construction techniques of residential houses of the Tibetan villages. Then, the author analyzes and collects building skills from the perspective of architecture.
\end{abstract}

\section{Keywords}

Architectural Construction Techniques, Tibetan Villages, Saiergu Tibetan Villages, Construction Techniques of Tibetan Villages

\section{Introduction}

Since beginning from the second half of the $20^{\text {th }}$ century, the tide of rising urbanization has promoted the whole world pattern to change at an alarming rate. This expansion is so short-term and rapid that it makes difficult for cities to adapt. What's more, traditional rural settlements do not have time to make a reaction, which leads to decline and wane at the same rate [1]. Traditional houses are eroded unprecedentedly. More and more experts, scholars, and professionals concerning in the field are now giving great emphasis on the return of 
traditional architectural culture. Residential houses with local features and individuality are becoming one of focal points of contemporary architecture, and have gradually developed into a source of regional architectural creation. As a kind of local architecture with breeding folk culture, traditional residential houses have localized "traits" and belong to "architecture without architects" [2]. However, traditional residences are fusional products on the basis of indigenous native spirit and long-term accumulation of superb craftsmanship.

The construction of Tibetan houses also has its own unique artistic way. On the one hand, it shows the living space of the Tibetan people. On the other hand, it reflects the Tibetan people's living habits, religious drinking and aesthetic psychology, which is an expression of Tibetan history. Traditional residential buildings of Tibetan nationality have been applauded by domestic and international architectural fields for their solid, majestic, dignified and nice features. Raw materials for construction of Tibetan buildings, such as stones, wood and mud, are all taken from nature. Construction method is original and simple hand measurement method. It is impressed by the people all around the world that a strong building that has not been moved for 100 years is built only with simple material and wall building method. At the time when it comes to valuing and excavating national culture, it is worthwhile for us to make a research and develop traditional residences.

\section{Research on the Construction Techniques of Tibetan Villages in the Saiergu Town}

\subsection{Geographic Location}

Saiergu Tibetan villages are located in Heishui County of Aba Tibetan Autonomous Prefecture, which is the eastern gate of Heishui County. It is bordered Maoxian County on the southeast, only 38 kilometers away from the "Chengdu-Jiuzhaigou" main line. The distance from Tibetan villages to Chengdu is 240 kilometers and 60 kilometers away from the county town of Luhua. It has been a significant transportation centre for Heishui for thousands of years.

Site selection is an indispensable part of the folk culture of the Jiarong Tibetans. It follows the principle of "situated at the foot of a hill and beside a stream, facing to the south, and moderate terrain", adheres to the principle of "peopleoriented, people's house as home", and "productive soil and thriving crops" [3]. There are diverse ways to choose a site. Generally, it is to ask the local Aka, who is highly respected, to conduct it called "Dinglongmai". The first measurement is about mountain conditions and determines the location of houses. Then the direction of auspiciousness is measured in order to determine open direction of gates [4].

\subsection{Spatial Layout of Villages and Plan}

There are three stockaded villages (Zhai Zi) in Saiergu Town: Shangzhai Zi, Xiazhai Zi, and Doll Zhai Zi. Xiazhai Zi mainly reflects the underground defense 
system. Shangzhai Zi mainly defends its enemies by using steep terrain, and Doll Zhai Zi mainly reflects the air defense system. Tibetan villages of Saiergu were not made in one go, with a solid foundation. It has been built for one hundred years decorated with red, yellow and white colors [5]. Alleys are inlaid with stone pieces and dense ladders. The structure of the entire Tibetan villages is rigorous and households are connected. A clear stream is connected with the Zhailou Pavilion. In the event of an accident, deep and serene ancient canals become an important channel for safe passage and guarding against enemies, forming an indestructible defensive system.

Residential houses of Saiergu Tibetan village belong to stone buildings. Based on the topographic features of mountainous terrain, Tibetan residences are distributed in high and low rank, in the direction of branches of mountains and the river arrangement. Whether it is the whole or individual structure, it shows a free and multi-faceted and irregular space layout. The planes of residential houses are generally rectangular, usually divided into three layers. There is a saying that "humans are beyond beasts and God is beyond the humans." Therefore, the ground floor is a place for livestock shed, and the second floor is a living room and kitchen. The second and third floors are accommodated. Living room has a hall. The north of the top floor is a warehouse, the front of which is a drying platform. Outside of the third floor lies a corridor and a drying rack (also has railings). The roof is a flat.

\subsection{Building Materials}

Construction characteristics of the Tibetan residential building materials are "local material for on-site construction", which have greatly reduced the construction cost of residential buildings in the economically underdeveloped mountainous areas. The building materials used in residential houses are gneiss. Gneiss is thick with high strength, good toughness. It can withstand various loads such as shock and vibration. The stone material after mining belongs to blank material and requires different processing of thicknesses: trimming, looting, roughing, picking, cutting, polishing and special processing.

As the most primitive building material, the sand is plentiful. Based on the granularity and material composition of the sandstone, a moderately-selected building material is selected. They can be applied to bonding and jointing between the stones. Wood is used to separate space and floors. Different functional spaces are separated by wood boards, then merged into slabs with planks. Vertical traffic is done with wood.

\subsection{Base}

The bases of residential houses of Tibetan villages in Saiergu Town are formed by the terrain. Because of rising and falling mountainous terrain, the location of the dwellings changes along with the height difference. Hill slopes are reorganized into terraces of different heights by "digging" and "filling". Houses are 
built on the terrace. The mountain rock is the natural foundation of the Tibetan village dwellings. The irregularities only need to be selected and mined to form a large block of stone on the foundation. They are simply stacked to form a platform to transfer the house load to the rock. This method of building a platform forms the integration of yard walls and walls base. The low-lying platform is connected to high-walled courtyard. At the same time, enclosed streets and lanes are formed. Multi-level transportation network is set up [6].

\subsection{Structural System and Masonry for Walls}

Partial pressure column serves as the load-bearing structure for the entire building. Walls are built by hand, which is prominent angular form in the corners of the wall. This technique is known as the best one for the Jiarong Tibetans. It is the load-bearing center for the entire house, equivalent to the spine of the human body. It is acclaimed as "architectural myth" by relevant experts.

The masonry of wall is generally a mortar, which means that clay mortar is required to be mixed as a binder. The gneiss is piled up. The raft and mud are sewed. The method of straightness in internal part and outward receiving is used for mansonry of walls. The thickness of walls is 0.8 meters and the top is 0.5 meters. Different forms of stone are arranged in the masonry process to form various masonry forms. However, they must be overlapped with missing gap to avoid straight seams, which ensure the strength and stability of walls.

In addition, there are some special node structures on the wall. For instance, a large square bar is used at the corners, and they are directly connected to each other to form a right angle. It is similar to modern method of spurs to ensure stability. The form of overlapping wall is only to satisfy with compression resistance, because it may be easy to collapse [7]. Workers press into large stones to stabilize the structure at a distance in the middle of the wall. Most of the gates near the gate have a humming stone. This kind of construction can be traced back to the era of horse riding. Some people put a hole stone on the wall facing the street. It is used for fastening horses and donkeys. Such structure is practical and decorative. The structure is very simple so that a tether can be tied.

\subsection{Structure of Roofs, Doors and Windows}

The roof beams are half-divided or herringbone-shaped on both sides, which are similar to tiny buildings with green roofs. The fir boards opened on the stand cover of fir are also known as tile plates. They are about $1-1.5$ meters long, 5 to 8 inches wide covered with slate press joints after the cover boards are closed to achieve fixed oblique flat drainage. Each layer of roof is made up of a thick tree bar, and beams are laid vertically. The two ends of beams are built in the stone wall. The beam is covered with sticks. They are called "handle" by the local people, and then branches are added. The local people call them as "Zhazi". Then the mud is tightly packed. The top floor is composed of wooden boards as the upper floor, while the roof is made of earth and rock as the roof. This tradi- 
tional practice still maintains until today.

Because of the limitation for landform, the buildings are arranged according to the terrain and size of construction areas. The external walls of building depend on mountains as walls. Therefore, the entrances and exits of buildings are also built by the landscape. "Door" is the symbol of social hierarchy, which marks the identity, status, and wealth of owners. The concept of doors with various grade is weakened in mountainous areas where conditions are limited. Height of doors is not high, only about 1.8 meters, which are made of wood. White stone is placed above the threshold, symbolizing the White Stone God of the Jiarong Tibetans, and praying for life safety of their families. Hanging prayer flags on the door, it means that when the head touches once, it indicates that the chanting should be done once, so that evil things can be impeded outside the house.

Walls above the second floor open a lot of window holes of various sizes. All of them are made of stone. A slot is left outside, while the inside is fan-shaped. It looks like a horn shape from inside to outside. It is bright inside and not easy to find from outside. It is convenient to observe shooting at wartime or suffering unexpected events. This sewing hole has three usages. They are used for shooting holes, spotlight, warmth conservation.

\subsection{Suitability Technology}

Besides traffic function, main function of three-dimensional street of Tibetan villages in Saiergu Town is drainage. The drainage system extends to all directions and runs through the entire village. The groundwater network is hidden behind houses of many families. In ancient times, although enemies invaded the entire village, ancestors can also survive in the houses. Because water and grain were available, ancient ancestors of Saiergu Town used groundwater net to attack enemies several times. This type of water network are arranged throughout the entire village Where there are dark ditches and open ditches. These simple designs not only facilitate self-drainage of domestic water, but also prevent excessive water from being discharged into streets and alleys when it rained. It can prevent muddy roads and facilitate flood discharge. Through the intertwining of the entire village and masonry channels along streets, an effective drainage system has naturally been formed.

Taking into account the cold-proof and moisture-proof, the main construction methods used for residential buildings of the Tibetan villages in Saiergu Town are: outer walls are tough and tight; unique window technology is used for the south-facing wall; solar energy is fully used in the winter. For the northern and western walls, the opening time for windows should be reduced. The enclosure between mountains and buildings reduce the air flow and reduce the heat loss.

Due to significant temperature difference between day and night, especially in the cold winter, insulation is particularly important. Limited by the structure, 
small rooms, thick walls and small windows of houses, it may be fully insulated and effectively resists the cold northwestern wind in winter, thereby achieving the effect of being warm in winter and cool in summer. In addition to some construction measures, some artificial measures are also adopted which are better than entering fire pits in the house. When cooking and boiling water in winter, they can provide heat through fire pits.

\section{The Dilemma of the construction of Tibetan Villages in Saiergu Town}

The construction of residential houses is rarely recorded in historical records. The construction of residential houses is handmade craftsmanship [8]. It is also called a "craftsmanship," which relies on craftsmen. There are no actual drawings in the construction process. All of them are kept in the minds of craftsmen. The scale of construction and other experiences are accumulated by old craftsmen for many years. Experienced construction craftsmen put their heads in a position to control the entire construction process, such as the size, progress, and quality of the house. With development of traditional Tibetan villages in Aba, it is no longer necessary to use traditional construction technique of masonry houses. The young people feel that it is useless to learn ancient skills. Craftsmen who are involved in traditional residential houses of Tibetan villages are now very precious and face the situation that no one can succeed their skill. Therefore, it is particularly valuable to inherit and retain the construction skills of Tibetan Village. So, the author hopes to record the construction process of Saiergu Tibetan walled houses in detail through specific words and drawings, to provide some reference for the future scientific research or construction process.

\section{Conclusions}

As an ecological local building with original feature, traditional residential houses of Tibetan villages are important carriers of regional history, Feng Shui concepts, religious awareness, folk customs, economic development, and other human geography. It is also the architecture style which reflects regional environment features of Tibetan villages in Saiergu Town.

The Tibetan villages in the Saiergu region experienced baptism of more than a hundred years or even longer, and there are still simple people living in them. During the course of investigation, when seeing the stone house that had not been demolished was quietly and peacefully located at the foot of the big mountain after the earthquake, a picture of the life of the countryside in the mountains occurred in my mind. Traditional residential houses and villagers who are leisure and pleasant show us primitive and warm lifestyle.

However, from the survey, we have found that most of the residents in the Tibetan villages have been relocated, and most of the people who stayed in the Tibetan villages are senior citizen. Although traditional residences are preserved, new brick and tile houses are also under construction. To our pleasure, in recent 
years, people have begun to realize the significance of traditional culture and pay attention to the protection and inheritance of traditional residences. In this paper, the author establishes a relatively complete theoretical framework for the construction of residential houses of Tibetan villages in the Saiergu region. It aims to provide reference for future researches on the residential houses of $\mathrm{Ti}$ betan villages in the Saiergu Town or Aba Tibetan villages.

\section{Conflicts of Interest}

The authors declare no conflicts of interest regarding the publication of this paper.

\section{References}

[1] Luo, G. (2016) Dan Ba Jiarong Tibetan House. Chong Qing Architecture, 15, 65.

[2] Ye, Q.S. (1989) Tibetan Residence in Sichuan. China Building Industry Press, Beijing.

[3] Li, M.T. (2018) Study on the Architectural Adaptability of Jiarong Tibetan Traditional Settlement Culture Taking Xisuo Village as an Example. Pay Taxes, No. 6, 241.

[4] Wei, Q. (2002) Tibetan Religion and Culture. Central University for Nationalities Press, Beijing.

[5] Li, J.H., Xia, Y. and Zhang, Y. (2016) Defensive Settlement House of Tibetan Villages in Saiergu Town. Architecture and Culture, No. 11, 214-216.

[6] Liu, Y., Feng, M. and Ben, J. (2008) Taofu Tibetan Multiculturalism on the Banks of Fresh Water. China Industrial Press, Beijing.

[7] Zhang, Y. and Li, J.H. (2015) Discussion on the Protection and Development of the Settlement of Saiergu Town Folk House. Architecture and Culture, No. 7, 106-109.

[8] Tang, H.W., Jin, C. and Li, X.C. (2018) On the Value and Development of the Settlement in Saiergu Town Residential Area. Study on the Theory of Urban Construction (Electronic Version), No. 8, 202. 